\title{
INSTALLATION OF EQUILIBRIUM PRESSURE OF MILKING MACHINE VACUUM SYSTEM
}

Oleksandr Medvedskyi ${ }^{1}$, Saveliy Kukharets ${ }^{1}$, Gennadii Golub ${ }^{2}$, Vasyl Dmytriv ${ }^{3}$ ${ }^{1}$ Zhytomyr National Agroecological University, Ukraine; ${ }^{2}$ National University of Life and Environmental Sciences of Ukraine, Ukraine; ${ }^{3}$ Lviv National Agrarian University, Ukraine aleksmedvedsky@gmail.com, saveliy_76@ukr.net, gagolub@ukr.net,dmytriv_v@ukr.net

\begin{abstract}
While designing the vacuum system of a milking machine it is necessary to study the influence of structural element parameters on the level of vacuum metric pressure. In particular, a long-lasting action of pressure, different from a standard one, affects the operating performance of a milking machine, and it can result in negative consequences on cows' wellbeing. That is why a structural and a technological scheme of a vacuum system must provide fast pressure stabilization. It has been determined that the operating performance of a vacuum system of a milking machine has a non-stationary nature. It has been stipulated by combining structural elements with wide range of pressure into one system. A temporary access to pressure of higher potential has a significant effect on the pressure level in a vacuum system. The method of classic calculations of a vacuum system does not take this peculiarity into consideration. The determination of duration of both balanced and stabilizing periods is of great importance for efficient machine milking. It has been determined that a higher volume of a vacuum net is characterized by less pressure losses. The study of the effects of the parameters of a vacuum system on the level of a balanced pressure has been conducted. It has been scientifically concluded that a vacuum net permeability effects the duration of a balanced state of a vacuum system. The mathematic model of a balanced pressure dynamics of a vacuum system has been received. It has been proved that a balanced pressure of a vacuum system depends on both the constructional and the technological parameters of its structural elements. The mathematic model of the dynamics of pressure of the vacuum system stabilization has been determined. The nature of a balanced pressure effects on the duration of a stabilizing period has been revealed. A rational balance between the parameters of the vacuum system elements has been determined.
\end{abstract}

Keywords: pressure dynamics, total pressure, vacuum balloon, milk container, flow output.

\section{Introduction}

The constructional and functional schemes of a vacuum system are determined by a set of structural elements with own technological and geometric parameters. Classic calculating, according to the vacuum machine arrangement, lies in determining the pressure distribution among the given vacuum system elements [1]. Herewith, only one air stream regime is permissible - a stationary one [2]. Each approach is expedient to use when calculating the vacuum wired network of a closed-circuit vacuum system. Under deviation from the stationary regime of a vacuum system functioning there are difficulties in calculus. It is especially vivid for the systems, which combine a few technological containers, each of which has different level of primary pressure. In this case, it is important to determine the characteristics of both balanced and updated regimes.

The vacuum system of a milking machine is of an open type. The milking machine functioning requires periodic short-term access to higher potential pressure. A periodic combining of a vacuum system with atmosphere pressure causes immediate pressure boost, which does not correspond to primary regulated rate. Considerable pressure fluctuations in a vacuum network cause changes in the working regimes of operating mechanisms, the milking process duration increases, the milking completeness as well as fat content in milk decrease, a danger of garget disease rate emerges [3-6]. An efficient vacuum system should provide a permissible, according to the requirements of ISO 5707 [7], amplitude of pressure fluctuation in the vacuum network.

Pressure stability in a vacuum line is of great importance for efficient functioning of a milking machine [8-9]. The research [10] points at a positive effect of an increased volume of a vacuum network on the decrease in the level of pressure losses. However, the effects of the vacuum system parameters, which constituents have different primary pressure levels, on the pressure stabilization dynamics in a vacuum line were not studied.

\section{Materials and methods}

The purpose of the studies is to determine the effects of the constituents' parameters of a vacuum system in a milking machine on the pressure dynamics in a vacuum network. To do it, it is necessary 
to determine the interconnection between the speed parameters of an air stream and the volume of the constituents in the vacuum system. The research methods are based on the application of the theory of mathematic simulation with the use of the main points of integral and differential calculus, the main points of fluid and gas dynamics and of vacuum machines.

The balanced period lasts from the moment of volumes combining with different pressure levels up to the moment of establishing a total pressure in the vacuum system, which is common to all its elements. A total pressure in the vacuum system determines its balanced state, which occurs as a result of air redistribution in the whole volume and depends on time response of the vacuum network. Differential equation of a balanced pressure dynamics of a vacuum network is:

$$
\frac{d p}{d t}=\frac{\Delta p}{\tau_{1}},
$$

where $\Delta p$ - the rate of pressure change in a vacuum network, $\mathrm{kPa}$;

$\tau_{1}$ - time response of a vacuum network during a balanced period, $\mathrm{s}$.

After integrating of an equation (1), we will have:

$$
\ln \left(p_{s}-p_{p}\right)-\ln C_{1}=\frac{1}{\tau_{1}} \cdot t+C_{2},
$$

where $p_{s}$ - total pressure of a balanced state of a vacuum system, $\mathrm{kPa}$;

$p_{p}-$ working pressure in a vacuum network, $\mathrm{kPa}$;

$t$ - continuous time, s.

Balanced pressure of a vacuum system depends on constructional and technological parameters of its structural elements. On the basis of an experiment we can write down:

$$
p_{s}=\frac{p_{m} \cdot\left[V_{m}+V_{p c} \cdot \sigma+V \cdot \sigma\right]}{2 \cdot V},
$$

where $p_{m}$ - primary pressure in a milking container, $\mathrm{kPa}$;

$\sigma$ - ratio between primary pressure of structural elements, $\sigma=p_{p} / p_{m}$;

$V_{p c}$ - vacuum network volume, $\mathrm{m}^{3}$;

$V_{m}$ - free of milk volume of a milk container, $\mathrm{m}^{3}$;

$V$ - vacuum system volume $\left(V=V_{m}+V_{p c}\right), \mathrm{m}^{3}$.

Balanced pressure differs from the working pressure of a vacuum network $50 \mathrm{kPa}$ (Fig. 1) by the size of $\Delta p$. Greater volume of a vacuum network corresponds to lower level of the balanced pressure. Balanced pressure is higher in vacuum systems with a greater volume of the milk container on account of increase in partial pressure, irrespective of the vacuum balloon volume.

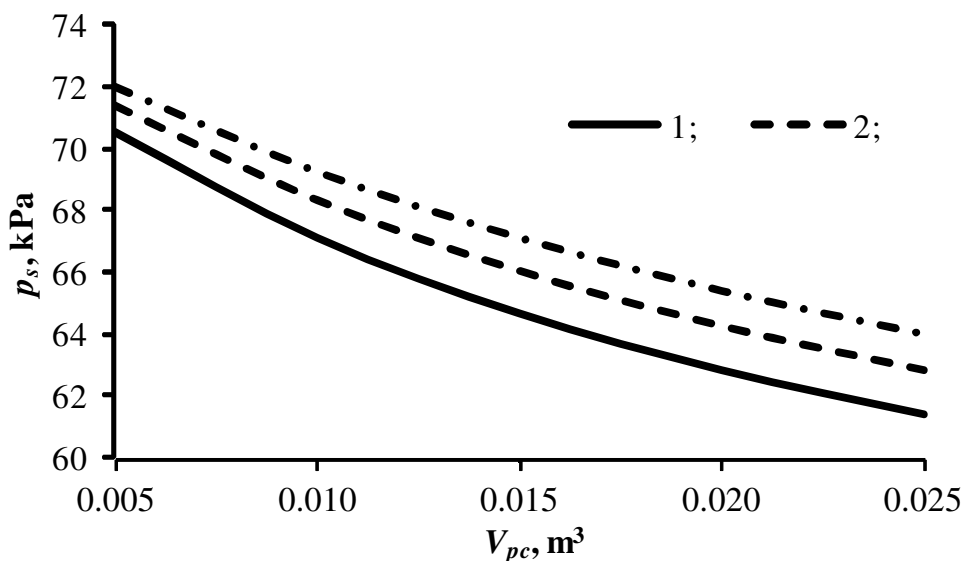

Fig. 1. Dependence of balanced pressure on vacuum network volume:

$$
1-V_{m}=0.020 \mathrm{~m}^{3} ; 2-V_{m}=0.025 \mathrm{~m}^{3} ; 3-V_{m}=0.030 \mathrm{~m}^{3}
$$


The duration of a balanced period depends on the intensity of air mass concentrations' balancing of vacuum system's volumes with different pressure levels. According to the recommendations [1; 11], time response will equal to:

$$
\tau_{1}=\frac{V^{m}}{Q_{m}},
$$

where $Q_{m}$ - intensity of a volume air consumption among structural elements with different pressure levels, $\mathrm{m}^{3} \cdot \mathrm{s}^{-1}$;

$V^{m}$ - air volume, which changes pressure in a vacuum network by the size $\Delta p, \mathrm{~m}^{3}$.

The results of the previous studies [10] make it possible to determine a necessary air volume to reach a balanced state of a system:

$$
V^{m}=\frac{2 \cdot V_{p c}\left(p_{s}-p_{p}\right)}{p_{s}} .
$$

The intensity of volume air consumption in a vacuum network depends on the level of pressure in the volumes of structural elements of a vacuum system. With due regards to Bernully and Klapeyron's equations [2], we will write:

$$
Q_{m}=\sqrt{\frac{2 \cdot\left(p_{m}-p_{p}\right) \cdot R T}{p_{m}}} \cdot S,
$$

where $S$ - cross sectional area of a vacuum-wired system, $\mathrm{m}^{2}$;

$R$ - specific gaseous air constant, $\mathrm{kJ} \cdot(\mathrm{kg} \cdot \mathrm{K})^{-1}$;

$T$ - absolute air temperature, $\mathrm{K}$.

Under initial conditions, under $t=0$, total pressure is determined by the working pressure in a vacuum network, constant integrating is determined by $C_{1}=\Delta p, C_{2}=0$. Potentiating the equations (2) and taking into consideration the equation (4), the solution to the equation (1) will be:

$$
p=p_{s}-\Delta p \cdot e^{-\frac{Q_{m}}{V^{m} \cdot t}}
$$

where $p$-pressure in a vacuum network during a balanced period at the moment of time $t, \mathrm{kPa}$.

The completeness of a balanced period is characterized by the same level of pressure in all structural elements of a vacuum system. The process of renewing of a working pressure in a vacuum network starts from the moment of reaching the balanced pressure.

When determining the duration of a renewal period, the process of air pumping out from the vacuum system will be considered as quasi-stationary [2]. For a period of time $d t$ some amount of air is pumped out of the vacuum system, as a result it causes change of the pressure on $d p$. A differential balance equation is:

$$
d p \cdot V=Q_{v} \cdot p \cdot d t,
$$

where $Q_{v}$ - intensity of a volume air loss of a vacuum system, $\mathrm{m}^{3} \cdot \mathrm{s}^{-1}$.

The main equation of vacuum machinery $[1 ; 11]$ connects the vacuum pump productivity and the intensity of a working pressure establishing a vacuum system:

$$
Q_{v}=\frac{Q_{p} \Sigma U}{Q_{p}+\Sigma U},
$$

where $Q_{p}$ - vacuum pump productivity, $\mathrm{m}^{3} \cdot \mathrm{s}^{-1}$;

$\Sigma U$ - vacuum system conductivity, $\mathrm{m}^{3} \cdot \mathrm{s}^{-1}$.

The equation solution (8) according to $t$ characterizes the duration of a renewal period: 


$$
t_{r}=\frac{V\left(Q_{p}+\Sigma U\right)}{Q_{p} \Sigma U} \ln \frac{p_{S}-p_{i n}}{p_{p}-p_{i n}},
$$

where $t_{r}$-duration of a renewal period, s;

$p_{\text {in }}$ - pressure of external air leak into a vacuum system, $\mathrm{kPa}$.

Graphical presentation of differential equations (1) and (8) as for the pressure $p$ shows pressure dynamics of a vacuum network during balanced and renewal periods (Fig. 2).

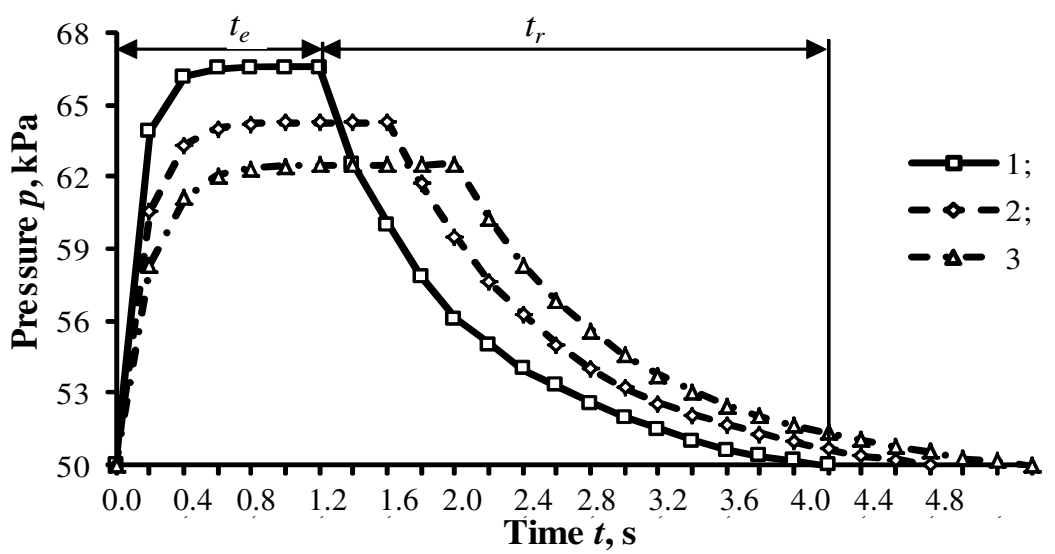

Fig. 2. Pressure dynamics in vacuum system: $1-V=0.030 \mathrm{~m}^{3} ; 2-V=0.035 \mathrm{~m}^{3} ; 3-V=0.040 \mathrm{~m}^{3}$; $t_{e}$ - balanced period, $\mathrm{s} ; t_{r}-$ renewal period, $\mathrm{s}$

The results of the research indicate at the interaction of a vacuum system constituents and pressure level in the network (Fig. 2). During a balanced period, pressure in the network increases up to the rate of total pressure of the vacuum system on the logarithmic law. Greater volume of a vacuum system corresponds to a lower level of total pressure, but the period of its establishing increases. It can be explained by an increase in time response of a vacuum system because of a decrease in the intensity of a volume air stream by means of the decrease in crucial pressure difference. The duration of a renewal period increases, when the volume of the vacuum network increases on account of a higher volume of the vacuum balloon. During the working process the volume of the milk container was $0.020 \mathrm{~m}^{3}$, and the level of the working pressure was $-p_{p}=50 \mathrm{kPa}$ (Fig. 2).

\section{Results and discussion}

The vacuum system constituents of a mobile milking machine affect the character of a vacuum pressure change in a vacuum network. The correlation of volumes of the vacuum system's elements determines the level of balanced state.

Balanced vacuum pressure of a vacuum network can be determined by the formula:

$$
p_{s v}=p_{a}-p_{s}=p_{p v}\left(1-\frac{V_{m}}{2 \cdot V}\right)=p_{p v}\left(1-k_{v}\right),
$$

where $p_{s v}$ - balanced vacuum pressure, $\mathrm{kPa}$;

$p_{a}-$ atmosphere pressure, $\mathrm{kPa}$;

$p_{p v}$ - working vacuum pressure of a vacuum network, $\mathrm{kPa}$;

$k_{v}$ - rate coefficient of constituents' volumes of a vacuum system.

Thus, balanced vacuum pressure depends on the volume correlation of the vacuum system constituents. Change of a multiplicity coefficient can result in a rational correlation between the vacuum balloon volume and the milk pail volume. Herewith, a higher level of balanced vacuum pressure is more accepted, as it forms a lower level of pressure losses, and higher stability of operating mechanism functioning is provided.

The adequateness of an analytical model (11) was checked by means of an experimental research. Strain sensors of pressure IPD-2-0.06, a comparison element with an intensifier TOPAZ 3-0.2 and a 
self-recording device H 3021-3 were used. Insignificant difference between the theoretical $y_{t}=f(x)$ and experimental $y_{e}=f(x)$ functional dependences was revealed (Fig. 3).

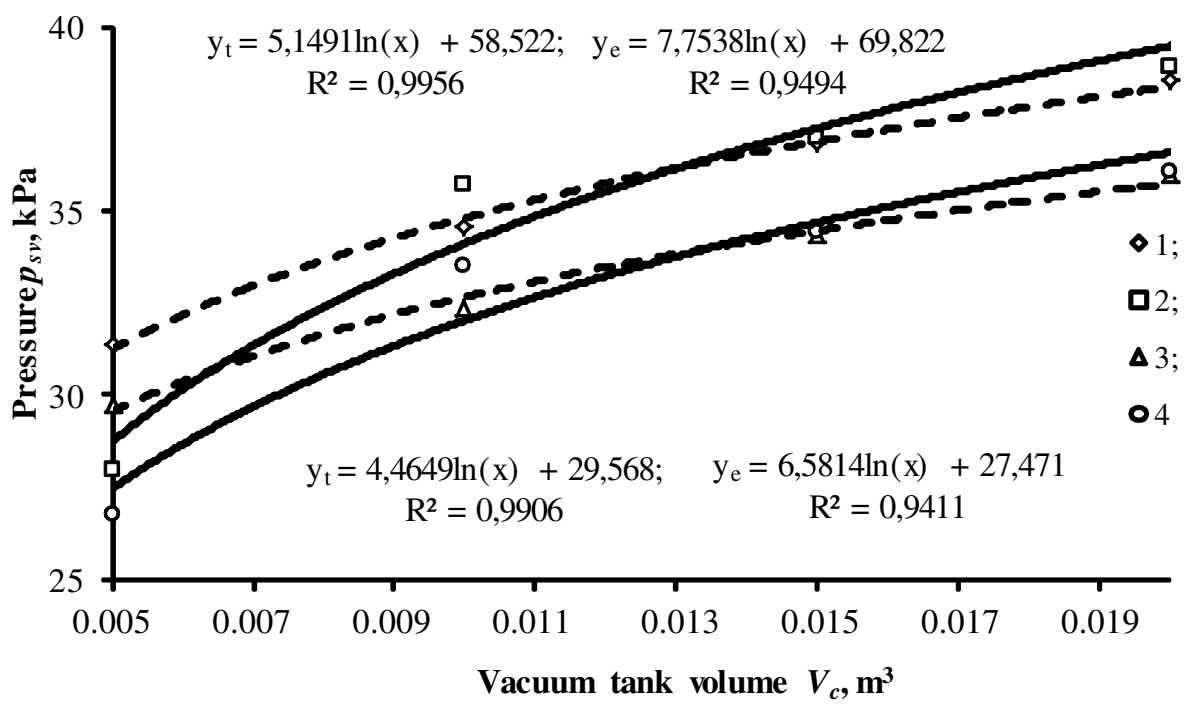

Fig. 3. Theoretical $(1 ; 3)$ and experimental $(2 ; 5)$ data of balanced vacuum pressure:

$$
1,2-V_{m}=0.020 \mathrm{~m}^{3} ; 3,4-V_{m}=0.030 \mathrm{~m}^{3}
$$

Experimental and theoretical curves are of the same character, irrespective of the volume of a milk container (Fig. 3). There has been observed an insignificant deviation by $9.92-10.78 \%$ under condition of minimal volume of a vacuum network. It can be explained by lack of indices in the equation (11), which take into consideration both particularities of the geometrical parameters and the structure of an air network. A rather high index of a determination coefficient indicates at the interrelation between the volumes of the vacuum system elements and the balanced state.

The vacuum balloon volume and the level of the working vacuum pressure nonlinearly effect the balanced state duration $\left(t_{e}\right)$. An empiric equation (12) has been experimentally established, it indicates at a quadratic dependence of a balanced period duration on the multiplicity coefficient of volume correlation (Fig. 4):

$$
t_{e}=520.61 k_{v}^{3}-634.45 k_{v}^{2}+238.14 k_{v}-25.58 .
$$

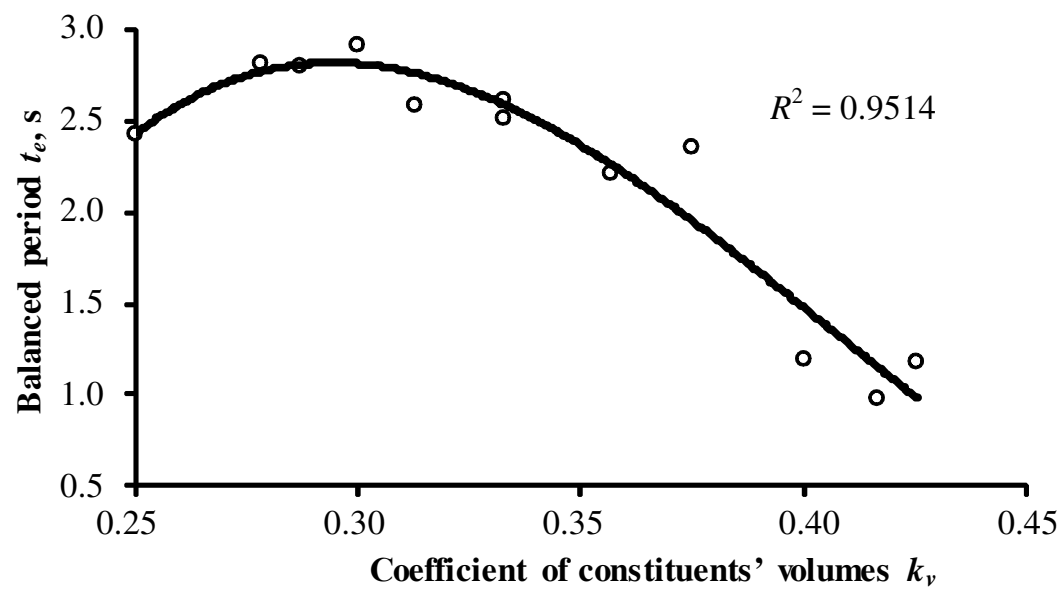

Fig. 4. Experimental data of balanced period under condition of $p_{s v}=50 \mathrm{kPa}$

The data of the experimental research indicate at a relatively identical balanced period in the range of the multiplicity coefficient of volume correlation $k_{v}=0.25-0.33$ (Fig. 4). The decrease in the balanced period duration under further increase of the $k_{v}$, coefficient takes place on account of the vacuum balloon volume decrease. At the same time the level of the balanced pressure decreases, it causes significant pressure fluctuations and reluctant changes of the working regimes of the operating 
mechanisms. That is why the correlation of the vacuum system's volumes should be agreed with the technological parameters of a milking machine.

\section{Conclusions}

1. Mobile milking machines have not been sufficiently studied as for the effects of structural elements' volume of a vacuum system on the duration of the constituents of the stabilization period. Studying the problem promotes to better understanding of pressure dynamics of a vacuum network. Considering pressure dynamics of the system of technological volumes with different initial pressure levels is of great importance at the stage of a mobile milking machine designing.

2. It has been established that the intensity and amplitude of pressure fluctuation of a vacuum network depend on the level of the balanced pressure as well as on the stabilization period duration. In the structure of the stabilization period 28-37\% of time is spent on establishing of the balanced state of the vacuum system. Within the range of the working vacuum pressure of 45$48 \mathrm{kPa}$ the duration of the balanced period is stabilized during 2.4-2.6 s under the vacuum balloon volume in the range of $V_{c}=0.015-0.020 \mathrm{~m}^{3}$. The lower level of the vacuum pressure corresponds to a shorter by 11-20\% duration of the balanced period. The reserve for the decrease in time consumption can be the adaptation of the vacuum wired network to the vacuum pump productivity.

3. A substantiated choice of technological and constructional volumes of the vacuum system constituents is of great importance. It has been proved that under condition of the coefficient of volume correlation on the level of $k_{v}=0.25-0.33$ is achieved a maximal stability of the vacuum pressure in the vacuum line of a mobile milking machine.

\section{References}

[1] Пипко А.И., Плисковский В.Я., Пенчко Е.А. Теоретические основы вакуумной техники (Technical grounds of Vacuum Machinery). Москва : Энергоиздат, 1988. 340 c. (In Russian).

[2] Лойцянский Л.Г. Механика жидкости и газа (Mechanics of liquid and gas). Москва : Дрофа, 2003. 840 c. (In Russian).

[3] Besier J., Bruckmaier R. Vacuum levels and milk-flow-dependent vacuum drops affect machine milking performance and teat condition in dairy cows. Journal of Dairy Science, vol. 99, 2016, pp. 3096-3102. doi.org/10.3168/jds.2015-10340.

[4] Rose-Meierhöfer S, Müller A., Mittmann L. etc. Effects of quarter individual and conventional milking systems on teat condition. Preventive Veterinary Medicine, 2014, vol. 113, pp. 556-564.

[5] Hovinen M., Pyörälä S. Invited review: udder health of dairy cows in automatic milking. Journal of Dairy Science, 2011, vol. 94, pp. 547-562. doi:10.3168/jds.2010-3556.

[6] Graeme A. The Role of the Milking Machine in Mastitis Control. Veterinary Clinics of North America: Food Animal Practice, 2012, vol. 28, pp. 307-320. doi.org/10.1016/j.cvfa.2012.03.004.

[7] ISO 5707: 1983. Установки доильные. Конструкция и техническая характеристика. (Milking Machines. Construction and Technical Characteristics). Москва : Издательство стандартов, 1991. (In Russian).

[8] Besier J., Lindb O., Bruckmaier R. Dynamics of teat-end vacuum during machine milking: types, causes and impacts on teat condition and udder health - a literature review. Journal of Applied Animal Research, 2016, vol. 44, pp. 263-272. doi.org/10.1080/09712119.2015.1031780.

[9] Nosal D., Bilgery E. Airborne noise, structure-borne sound (vibration) and vacuum stability of milking systems. Czech Journal of Animal Science, vol. 49, 2004, pp. 226-230.

[10] Медведский А.В. Влияние конструктивных параметров мобильной доильной установки на уровень вакуумметрического давления (The impact of the Constructive parameters of a mobile milking machine on the level of vacuum pressure). Motrol. Commission of motorization and energetics in agriculture, 2015, vol. 17, pp. 250-257. (In Russian).

[11]Фролов С., Минайчев В., Александрова А. Вакуумная техника: справочник (Vacuum Machinery. Reference book). Москва : Машиностроение, 1992. 480 c. (In Russian). 